\title{
CAPítTLLO 3
}

\section{"INDÚSTRIA DO ISOLAMENTO": UMA ANÁLISE DE PRODUÇõES ARTÍSTICAS MUSICAIS DURANTE A PANDEMIA DA COVID-19}

Maria Flávia Silveira Barbosa Camila Cristina dos Santos Éder Flávio Moura Bonfim

\section{INTRODUÇÃO}

Autores marxistas têm avaliado que vivemos a maior crise do capitalismo de todos os tempos (cf., por exemplo, Botelho, 2019; 2020 e Gouvêa, 2020) - embora concordem, também, que capitalismo é crise. A isso soma-se uma pandemia de proporções inesperadas. São mais de 108 milhões de casos confirmados em todo o mundo; mais de 9 milhões, em nosso país. Em número de óbitos, mais de 2,4 milhões e quase 240 mil, respectivamente, no mundo e no Brasil ${ }^{8}$, no momento em que finalizamos este artigo. O vírus, contudo, não é o responsável pela atual crise, como vem sendo justificado por alguns meios de comunicação e alguns governantes. Diz Gouvêa (2020, p. 19, grifos da autora):

não é verdade que a economia mundial "vinha se recuperando", ou "estava já quase bem”, quando, por uma fatalidade, algo terrivel e imprevisivel apareceu, lançan-

Dados da Johns Hopkins University. Disponível em: https://coronavirus.jhu.edu/map.html. Acesso em: 15.02.2021. 
do o mundo novamente na crise. Desde pelo menos 2018, uma nova onda daquela mesma crise precipitada em 2007-2008 já estava em curso e dava sinais de inédita profundidade. Esta nova onda irrompeu com o acirramento da disputa geopolítica entre Estados Unidos e China e era visível em termos imediatos no avanço do ultraconservadorismo pelo mundo, no ultranacionalismo, na explicitação da falência de 'instituições multilaterais', no acirramento da corrida armamentista entre EUA, China e Rússia e no enfrentamento militar direto em várias partes do mundo, inclusive através de Golpes de Estado, indicando a existência de uma disputa hegemônica travada em escala mundial através de guerras híbridas.

Evidentemente, não é o caso de afirmar que a pandemia não está provocando danos ou não irá trazer outros ainda maiores às já combalidas economias nacionais, em especial para os países da periferia do capital. Os desdobramentos da próxima ofensiva capitalista para recuperar suas taxas de lucro - que certamente virá dependerão da correlação de forças no âmbito da luta de classes; nada autoriza a pensar que será um período fácil, o pós-pandemia.

Ante essa calamitosa situação, o leitor pode se perguntar: por que falar sobre arte nesse momento? Outros temas não seriam mais urgentes? Dúvida certamente válida, mas o fato é que a pandemia tem provocado reflexões em e sobre os mais diferentes setores da vida social. E assumindo, como nós assumimos, uma concepção de arte que a considera como algo muito além de mero entretenimento, consideramos importante levantar aqui algumas questões. Assim, começaremos explicitando a dimensão humana sobre a qual desenvolveremos nossas reflexões, em contraposição ao entendimento de alguns governantes (locais, mas também mundo afora) que consideram a prioridade de "salvar a economia". Depois, apresentaremos a concepção de arte que aqui se assume, para tentar deixar delimitada a nossa compreensão acerca de sua função na vida das pessoas. Será preciso, também, localizar a produção artística na forma específica de organização societária em que vivemos - qual o sentido da produção artística no capitalismo e quais relações artista e obra de arte estabelecem com o público (ouvintes, leitores, espectadores etc.)? A seguir, traremos algumas informações sobre o trabalho de artistas a partir de meados de março; mais especificamente, lançaremos um olhar para o uso (quase que exclusivo, por conta da necessidade de isolamento físico) de tecnologias, como plataformas de compartilhamento de vídeos, redes sociais etc., por músicos brasileiros e estrangeiros. Esse material empírico será o ponto de partida para a reflexão sobre como os artistas têm se valido de tais recursos para concretar (ou não) a função da arte, que explicitamos. 


\title{
VIDA DILACERADA: 0 DRAMA HUMANO NO CAPITALISMO
}

Georges Politzer (1998) entende a vida humana como "drama”, não no sentido emotivo, romântico do termo, como ele mesmo explica, mas como sinônimo de ação, fato ou acontecimento, remontando à raiz etimológica grega. Ações, fatos, acontecimentos são vividos por indivíduos singulares, concretos - completamos: em suas relações com outros indivíduos e com o mundo. Por isso mesmo, no âmbito do estudo em que elabora essas formulações, com vistas à construção de uma psicologia concreta, livre das armadilhas metafísicas da psicologia clássica - armadilhas em relação às quais a psicanálise, o comportamentalismo e a teoria da Gestalt lograram alguns avanços, porém não a completa superação -, o autor destaca que a natureza do drama (objeto da psicologia concreta) não é interior. Como explica Bleger (1964, p. 35), Politzer deixa traçado um caminho para a compreensão de que "a psicologia está na vida cotidiana, nos seres humanos de carne e osso, estudados como tais nas situações de sua vida comum e diária".

Assim, entendendo "drama" como a vida que tocou a cada um viver, vamos nos permitir acrescentar ao conceito de Politzer a ideia de que, sob a determinação das relações sociais capitalistas, o drama da vida humana tem um caráter trágico. É necessário, porém, explicitar o que se entende por trágico. Vejamos com Sánchez Vázquez (1999, p. 245, grifos nossos), em sua reflexão sobre o trágico na vida real.

\begin{abstract}
A rigor, não cabe falar da tragicidade de algo real como a natureza, pois esta não é trágica em si mesma, mas apenas em certa relação do homem com ela. $\mathrm{O}$ trágico não está, por exemplo, na tempestade, no sismo ou no furacão que surpreendem, mas sim no homem que, diante desses fenômenos naturais, surpreendido ou horrorizado por eles, se vê numa situação trágica. A tragicidade é, pois, característica da existência humana. Não, na verdade, como um componente essencial ou constante dela, mas sim em certas relações do homem (individuos, grupos sociais ou povos) com o mundo, com a natureza ou em determinadas relações dos homens entre si. Nessas relações humanas ocorrem situações, comportamentos, atos ou resultados de suas ações que podemos classificar de trágicos.
\end{abstract}

Pensamos justamente que a relação sócio-metabólica enformada pelo modo de produção capitalista, sobretudo em sua fase atual, engendra, por razões que colocaremos a seguir, essa característica de tragicidade ao drama da vida humana. Foquemos um pouco no trecho em destaque da citação anterior, pensando nessas relações sob a égide do capital. A relação do homem com a natureza, nesse sistema de organização da vida, é tão deletéria que estamos a ponto de destruí-la, o que significa também a nossa própria destruição. A expansão das fronteiras 
agropecuárias sobre as florestas que ainda restam em nosso planeta ${ }^{9}$ tem se dado de maneira tão agressiva que permite a um vírus, que sobreviveu durante milhares de anos em certas espécies animais sem lhes causar qualquer dano, "pular" rapidamente para outras espécies que podem infectar mortalmente o ser humano. Essa não é a primeira pandemia do século e nem será a última. ${ }^{10}$

Que dizer, então, da relação do homem com os outros homens? Em uma sociedade na qual a riqueza "aparece como uma "enorme coleção de mercadorias"” (MARX, 2013, p. 113), as relações humanas assumem "a forma fantasmagórica de relação entre coisas" (Ibidem, p. 147). Sem nos darmos conta, somos reduzidos a produtores e consumidores de mercadorias, esquecemo-nos de que tais mercadorias são fruto do trabalho de outros homens, e, mesmo quando não estamos efetivamente em uma relação de troca, a mercantilização está presente e medeia os vínculos constituídos. Essa forma de sociabilidade é a base material da alienação:

o objeto que o trabalho produz, o seu produto, se lhe [ao trabalhador] defronta como um ser estranho, como um poder independente do produtor. O produto do trabalho é o trabalho que se fixou num objeto, fez-se coisal, é a objetivação do trabalho. A efetivação do trabalho é a sua objetivação. Esta efetivação do trabalho aparece ao estado nacional-econômico como desefetivação do trabalhador, a objetivação como perda do objeto e servidão ao objeto, a apropriação como estranhamento, como alienação (MARX, 2010, p. 80, grifos do autor).

Vê-se, então, porque o drama humano, a vida do homem, no capitalismo, é uma vida dilacerada. Quanto mais mercadorias produz, mais estranhas e alheias lhe parecem; quanto mais consome, mais é consumido por elas. O trabalho que fez de nós seres históricos ${ }^{11}$, e que produz toda a riqueza realmente existente, é também aquilo que nos despedaça.

A mercantilização de todos os aspectos da vida - visando não as necessidades propriamente humanas, mas a reprodução do capital -, no momento crucial que vivemos, inviabiliza o desenvolvimento de testes rápidos, de vacinas, a

\footnotetext{
9 Mas não só, também a construção de indústrias de outros setores tem sido responsável por essa devastação.

10 2002: Sars-Cov (SARS); 2009: H1N1 (gripe suína); 2012: Mers-Cov (MERS); para falar das ocorrências mais recentes. No entanto, é emblemático o caso do vírus Ebola que atinge a África desde 1976 e apenas recentemente se vislumbrou a possibilidade de uma vacina, ainda em fase de testes.

11 "O primeiro ato histórico é, pois, a produção dos meios para a satisfação dessas necessidades, a produção da própria vida material, e este é, sem dúvida, um ato histórico, uma condição fundamental de toda história, que, ainda hoje, assim como há milênios, tem de ser cumprida diariamente, a cada hora, simplesmente para manter os homens vivos” (MARX, 2007, p. 33).
} 
reconversão industrial para a produção de insumos, equipamentos de proteção pessoal, respiradores, leitos etc., e produz, com desculpas pela repetição, a odiosa ideia de "salvar a economia" antes das pessoas. "Com a valorização do mundo das coisas aumenta em proporção direta a desvalorização do mundo dos homens" (MARX, 2010, p. 80, grifos do autor). Isso é, definitivamente, trágico porque, na altura do desenvolvimento das forças produtivas em que se encontra a sociedade humana, existem plenas condições para que não seja assim. Fatos, acontecimentos - naturalizados (fetichizados), mas que, concretamente, resultam das relações humanas com o mundo natural e com os outros homens - assumem uma dimensão trágica porque seriam plenamente evitáveis se fossem outras as relações estabelecidas. Sánchez Vázquez (1978, p. 54) sintetiza assim a condição humana sob o capitalismo:

diferentemente do animal, que se relaciona de um modo unilateral com o mundo (sob forma imediata, forçosa e individual), o homem encontra-se numa relação múltipla, mediata e livre. Como ser humano, é tão mais rico quanto maior for a sua riqueza de relações, isto é, quanto mais sentir a necessidade de se apropriar da realidade sob infinitas formas. A riqueza humana é riqueza de necessidades, e riqueza de relações com o mundo. Sob o capitalismo, o homem torna-se um ser carente de necessidades, um ser que reduz sua vida à necessidade de se sustentar, ou que renuncia às suas necessidades humanas em favor de apenas uma: a necessidade de dinheiro.

Importa destacar a diferença entre a riqueza que consiste na acumulação de mercadorias e a riqueza entendida como "a necessidade de se apropriar da realidade sob infinitas formas"; uma dessas formas pode ser a arte. Vejamos, a seguir.

\section{UMA CONCEPÇÃO DE ARTE}

Em consonância com a perspectiva teórica que matriza este artigo, chamaremos agora ao debate dois autores marxistas que refletiram também sobre arte. São eles: Adolfo Sánchez Vázquez e Lev S. Vigotski; suas concepções vão nos ajudar a compreender 1) a essência da arte; 2) a natureza da reação estética; e 3) sua função na vida dos homens. Essa afirmação pode parecer reducionista e é, de fato, mas servirá ao nosso propósito aqui.

Sánchez Vázquez, em oposição a autores que entendem arte como ideologia e como forma de conhecimento de um modo estanque, segundo sua análise, formula a ideia da arte como criação: "reduzir a arte à ideologia ou a uma mera forma de conhecimento é esquecer que a obra artística é, antes de mais nada criação, manifestação do poder criador do homem" (SÁNCHEZ VÁZQUEZ, 1978, p. 
45). Evidentemente, não se deve vislumbrar nessa afirmação nem um átomo de idealismo; ao contrário, o autor formula essa ideia a partir de Marx, em seus Manuscritos econômico filosóficos de 1844. Nessa obra, Sánchez Vázquez encontra subsídios para compreender a "natureza criadora comum" (Ibidem, p. 47) entre arte e trabalho. Esse seria o "extrato mais profundo e originário [da arte]: o de ser uma forma peculiar de trabalho criador" (Ibidem, p. 47). Esse entendimento abarca, na opinião do autor, o reconhecimento da arte como forma de ideologia e como forma de conhecimento, sem excluir a sua verdadeira substância: a criação; e põe em relevo que arte e trabalho não são atividades antagônicas, mas partilham essa mesma essência ${ }^{12}$.

O psicólogo russo Lev S. Vigotski, ao formular sua teoria da reação estética, postula a arte como técnica social do sentimento. Vamos tentar compreender a ideia, destrinchando seus elementos. Técnica: acreditamos que Vigotski esteja se fundamentando em Marx para considerar a arte como objetivação de forças essenciais humanas, da mesma forma que o são os dispositivos técnicos, o conhecimento científico etc. O termo técnica coloca a arte em relação com outras técnicas e objetos criados pelo homem; o que a diferencia deles é tratar dos sentimentos. Social: diz o autor russo, em uma emblemática passagem, "a arte é o social em nós" (VIGOTSKI, 1998, p. 315); social é, pois, a raiz e a essência da arte. Na obra de arte, o artista objetiva seus sentimentos (que são de origem social, sempre) e um receptor deles se apropria, formando assim um duplo vetor: objetivação-subjetivação de sentimentos (sociais por sua natureza). Do sentimento: designa a especificidade da arte.

Continuemos um pouco mais com Vigotski. Para ele, o material que serve de base à criação da obra artística é a própria vida (acontecimentos, relações, caracteres, lugares, sentimentos etc.). $\mathrm{O}$ trabalho artístico consiste justamente em tomar esse material e transformá-lo em algo novo, que não estava nele ${ }^{13}$, a priori. Ao elaborar a obra de arte, o artista torna objetivos os sentimos, dá concretude a eles, o que possibilita ao fruidor se relacionar objetivamente com eles, quer dizer, como se fossem objetos, de maneira objetiva. Esse processo provoca naquele que aprecia a obra de arte uma transformação qualitativa dos próprios sentimentos, o que Vigotski entende como o verdadeiro efeito da obra de arte: a catarse. Essa

\footnotetext{
12 A um só tempo, postula arte como trabalho e trabalho como atividade criadora humana. Da configuração que ambos assumem no capitalismo, trataremos adiante.

13 Poderíamos acrescentar que, dialeticamente, não estava e estava, ao mesmo tempo; uma vez que, se houvesse uma desfiguração completa do material, não se poderia dizer que se trata desse ou daquele acontecimento, sentimento etc., e isso resultaria em uma concepção subjetivista da criação artística - nada mais distante da perspectiva vigotskiana.
} 
transformação qualitativa dos sentimentos (catarse) é por nós entendida como elaboração superior da consciência; em outras palavras, sentimentos comuns, contraditórios, caóticos têm, na fruição estética, a possibilidade de ser reelaborados no sentido de uma compreensão mais elevada da própria vida (ou do drama humano, como diria Politzer).

A vivência estética aproxima o indivíduo da experiência constituída historicamente por todo o gênero humano. Esse compartilhar de experiências humanas permite a superação da "nossa vida comum", como diz Vigotski em uma passagem sobre Hamlet, de Shakespeare:

\begin{abstract}
a tragédia pode obter esses efeitos incríveis [a catarse] sobre os nossos sentimentos precisamente porque os leva a transformar-se constantemente em seus opostos, a enganar-se em suas expectativas, a esbarrar em contradições, a desdobrar-se; e quando vivemos Hamlet temos a impressão de que vivemos milhares de vidas humanas em uma noite e, de fato, conseguimos experimentar mais emoções do que em anos inteiros da nossa vida comum (VIGOTSKI, 1998, p. 243).
\end{abstract}

Contudo, não é toda criação no campo da arte que carrega esse potencial de promover catarses. Na sociedade capitalista, a produção e o consumo de uma arte cuja função é apenas o entretenimento são infinitamente maiores. Não se trata de banir essa produção do campo da arte - esse seria o caminho fácil -, mas é preciso distinguir entre essa e a arte que promove a elevação das consciências - "as duas esferas desempenham papéis diferentes em suas relações com a vida cotidiana" (FREDERICO, 2013, p. 136). Arte-entretenimento, em oposição ao que foi dito anteriormente, mantém o indivíduo nos limites da cotidianidade e da individualidade alienada, não possibilita a apropriação de toda a riqueza ${ }^{14}$ do gênero humano.

Vejamos como Sánchez Vázquez analisa as relações entre arte e capitalismo a partir da afirmação de Marx: "assim se pode explicar que a produção capitalista seja hostil a certas produções de tipo artístico, tais como a arte e a poesia" (MARX apud SÁNCHEZ VÁZQUEZ, 1978, p. 169). Marx não desenvolve essa ideia, por isso Sánchez Vázquez se dedica a desvelar a origem e a essência. Apresentar aqui todas as descobertas do autor espanhol, mesmo que sucintamente, fugiria aos nossos propósitos. Assim, traremos apenas algumas delas para ajudar em nossas reflexões. Em primeiro lugar, é necessário deixar claro que a arte tem se desenvolvido, apesar da hostilidade capitalista. Isso é inegável! O entendimento marxiano é válido, portanto, para a produção artística que se encontra, por

14 Riqueza no sentido da citação de Sánchez Vázquez, na p. 5 deste artigo. Riqueza, portanto, que humaniza e não que escraviza. 
diferentes razões, sob o jugo dos critérios de produtividade capitalistas - trabalho assalariado, mercado, lucro etc.; também é verdade que alguns setores da arte estão mais sujeitos a essas leis que outros.

\footnotetext{
Quanto mais profundo é o interesse pela produtividade material da obra de arte interesse determinado, por sua vez, pelo montante do capital investido e dos lucros ou perdas em jogo - tanto mais limitada é a liberdade de criação, tanto mais dirigido é o processo de criação e tanto mais se tenta ajustá-lo a prescrições que assegurem sua aceitação por um público de massa (SÁNCHEZ VÁZQUEZ, 1978, p. 245).
}

Dois polos podem ser observados, de acordo com Sánchez Vázquez: por um lado, a hostilidade do capitalismo e, por outro, o desenvolvimento da arte. Esses polos não se relacionam de maneira estanque, imutável ou unidirecional, variam quanto ao período histórico, o grau de desenvolvimento da sociedade e as características de cada ramo artístico. Porém, a hostilidade se configura mais agressiva quanto mais se impõe à criação artística o jugo da produção material capitalista. Apesar de certa dificuldade em reduzir o trabalho artístico ao trabalho geral abstrato, na sociedade capitalista, a obra de arte tem, além de valor de uso - o que faz com que possa satisfazer necessidades humanas -, também valor de troca.

\footnotetext{
Convertida em mercadoria, a obra de arte perde sua significação humana, sua qualidade, sua relação com o homem. Seu valor - sua capacidade de satisfazer uma necessidade humana específica mediante suas qualidades estéticas - já não se funda nela mesma, e, portanto, em suas qualidades estéticas específicas, mas em sua capacidade de produzir lucro (SÁNCHEZ VÁZQUEZ, 1978, p. 216).
}

Analisemos ainda um outro ponto, com a ajuda de Sánchez Vázquez: a relação entre produção e consumo. Seguindo as formulações de Marx, o autor espanhol afirma a reciprocidade dessas relações. O consumo determina, em parte, a produção, porém a produção não se submete passivamente ao consumo e o determina sob três aspectos: 1) a produção engendra o consumo - sem a criação artística não haveria fruição; 2) a produção produz o modo de consumir o objeto; e 3) a produção estabelece a necessidade do produto criado. Sobreleva, aqui, a dupla capacidade criadora da arte: cria, ao mesmo tempo, o objeto e o sujeito da fruição. E, nesse sentido, coloca-se a possibilidade de criar justamente obras que promovam a elevação das consciências.

A lógica da propriedade privada, contudo, se sobrepõe a essa dupla capacidade. Premida pela necessidade de lucro, a criação artística vê-se tolhida, em sua liberdade de expressão, diante da exigência de ser consumida por um público sempre maior. Ocorre o que Sánchez Vázquez nomeia "estandartização"; o objeto 
artístico torna-se próprio para o consumo dos homens-massa ${ }^{15}$ - de fato, é produzido com essa finalidade -; torna-se, portanto, arte de massas. O autor assim delimita a arte de massas:

\begin{abstract}
neste tipo de produção pseudo-artística, os grandes problemas humanos e sociais são afastados, em favor de uma suposta necessidade de satisfazer um legítimo desejo de entretenimento, e, quando algum deles é mencionado, transita-se sempre pela superfície, com soluções que não abalam a confiança na ordem existente, empobrecendo as ideias, rebaixando os sentimentos e barateando as mais profundas paixões (SÁNCHEZ VÁZQUEZ, 1978, p. 278).
\end{abstract}

E logra alcançar tudo isso graças a

uma linguagem astutamente fácil, que corresponde à sua [do homem-massa] falta de profundidade humana; uma linguagem que assegura uma inteligibilidade e comunicação tão mais extensas quanto mais superficial e vazio for o seu conteúdo e quanto mais pobres, banais e débeis forem seus meios de expressão (SÁNCHEZ VÁZQUEZ, 1978, p. 278).

Finalizamos por aqui, com essa rápida apresentação do estudo de Sánchez Vázquez sobre os problemas da arte no capitalismo. Antes de passar para o próximo item, convém esclarecer que as colocações do autor acerca da arte de massas vão muito além da simples oposição erudito versus popular. De fato, não haveria interpretação mais equivocada de suas elaborações do que as reduzir a esse falso binômio. Mas essa questão terá que ficar para uma outra oportunidade.

\title{
REFLEXÕES A PARTIR DO CONCEITO DE INDÚSTRIA CULTURAL
}

Também T. W. Adorno e M. Horkheimer, ambos da Escola de Frankfurt, ajudam a compreender o problema da arte sob o capitalismo. A expressão indústria cultural foi utilizada originalmente no livro Dialética do esclarecimento (1985), com objetivo de identificar um fenômeno característico do capitalismo presente nas sociedades industriais do século XIX: a criação de um mercado consumidor de bens culturais, massificado, alienante e reprodutor, que vinha se estabelecendo há algumas décadas. Equivalente ao fetichismo da mercadoria, configura-se como a penetração do valor mercantil na produção dos bens culturais, sobretudo a partir da concentração do capital; essa indústria surge, então, juntamente com o capitalismo

15 "O homem ideal, do ponto de vista dos interesses deste capitalismo voraz, é o homem engendrado por suas próprias relações: isto é, o homem despersonalizado, desumanizado, oco por dentro, esvaziado de seu conteúdo concreto, vivo, que pode se deixar modelar docilmente por qualquer manipulador de consciências; em suma, o homem-massa" (SÁNCHEZ VÁZQUEZ, 1978, p. 276). 
monopolista. Adorno e Horkheimer, ao pensar nesse conceito, se preocuparam com o modo como a indústria cultural deformava a consciência do sujeito, pois, com esse instrumento, o capitalismo seria aceito, reproduzido e desejado. Indústria cultural tem correspondência com o conceito de indústria ideológica, desenvolvido por Ludovico Silva, em seu livro A mais-valia ideológica (2017). De acordo com o autor venezuelano, com a expressão cunhada por Adorno e Horkheimer ainda se pode ter a impressão de que existe cultura nessa indústria, mas, na verdade, trata-se apenas da deformação e justificação dos interesses de classes; logo, inteiramente ideológica. Podemos também observar uma correspondência com Pier P. Pasolini (1968) em uma das suas obras mais memoráveis, o filme Teorema ${ }^{16}$, no qual já se mostra o pensamento do autor na denominada homologação cultural, baseada no conceito de hegemonia de Antonio Gramsci, em que o sujeito afirma e deseja a ideologia dominante, tornando-se conformista e alienado.

Um pouco antes disso, J. Ortega y Gasset utilizou o conceito do homem-massa, em seu livro Rebelião das massas (1929), para se referir ao sujeito que ele identificava, naquele momento, na sociedade, como uma expressão do conformismo em relação às determinações exteriores. $\mathrm{O}$ indivíduo e sua individualidade saem de cena e dão lugar ao sujeito que busca enquadrar-se nas determinações genéricas do mundo social massificado (RODRIGUES, 2020). Sentindo-se confortável quando se vê igual a todo mundo, em conformidade com aqueles que o rodeiam, tornando-se passivo à vida cotidiana. No campo da arte, Sánchez Vázquez também se refere ao homem-massa, como vimos anteriormente, considerando a arte de massa, em sentido pejorativo, como uma pseudo-arte produzida de cima para baixo. De acordo com Sánchez Vázquez, ao contrário, a classe proletária, por estar em posição de reivindicação da essência humana, mereceria uma arte superior, emancipatória, e não seu antônimo.

Com a pós-revolução industrial (século XX), a produção se torna mecanizada, a maior parte dos operários e trabalhadores manuais em geral passa a poder desfrutar do tempo livre, havendo assim uma maior procura por atividades de entretenimento. Consequentemente, uma maior necessidade das classes dominantes controlarem e assegurarem não só seu poder na luta de classes, mas também impulsionar a soberania do capital pelas mesmas vias. Ou seja, percebe-se mais uma via para a disseminação da ideologia burguesa nos tecidos sociais por meio do consumo de entretenimento baseado nas artes integradas como um produto, estabelecendo

16 O filme italiano de 1968 retrata a história de um indivíduo e a sua influência em uma família burguesa. Curiosamente, cada membro da família representa uma instituição e um segmento da sociedade italiana. Através de suas personagens, o filme critica a futilidade, o comodismo e a alienação da burguesia. 
assim uma cultura de massa, na qual prevalece a orientação mercantil, em que o sucesso material é o valor predominante. Segundo Erich Fromm (2015), há pouca razão para surpresa no fato de seguirem as relações do amor humano os mesmos padrões de troca que governam os mercados de utilidades e de trabalho. Na concepção da indústria cultural, o homem é simplesmente um instrumento de trabalho e de consumo, transformando-se em objeto - sua coisificação. Trata-se de processo tão bem manipulado que até mesmo seu lazer se torna uma extensão do trabalho.

Ludovico Silva, no livro anteriormente referido, traz a reflexão de que esse entretenimento, na verdade, é preenchido pelo capital com mensagens de justificação do sistema, que aliena e impele o sujeito a continuar não só a ser explorado materialmente, como também o transforma em uma espécie de guardião da ordem burguesa. Ou seja, o trabalhador passa a ser defensor de uma ideologia que o prejudica e o mantém de joelhos. Logo, o processo de exploração do trabalho não somente extrai o trabalho excedente, mas também uma energia psíquica excedente.

Com o advento dos meios de comunicação de massa, alinhados à globalização, tornou-se possível a homogeneização cultural, importada das grandes potências mundiais, causando um enfraquecimento e ameaçando a cultura popular. Dentro do campo das artes, um exemplo prático disso seria o consumo da cultura veiculada por meio de plataformas de filmes e séries de TV. Nas telenovelas, destinadas aos homens-massa, a arte imita a vida e/ou a vida imita a arte, pois vendem-se personagens idealizados que, se aparecem fora do mundo televisivo (na "vida real"), serão aceitos, independentemente do meio em que estão inseridos.

O modelo e estilo de vida hollywoodiano, a presença majoritária de músicas em inglês nas rádios ou até mesmo essa idealização falsa nas telenovelas, citada anteriormente - em que, na maioria das vezes, não se retrata a realidade e a cultura do povo ou, quando o faz, é de forma romantizada, maquiando a desigualdade -, e tantos outros meios de propaganda persistem incansavelmente em um projeto de hegemonização de determinados aspectos culturais voltados para a sustentação e manutenção do sistema capitalista.

Se é verdade que a oferta condiciona a demanda, oferte-se sistematicamente o Programa do Faustão, aos domingos à noite, e a massa aceitará; ofertem-se filmes do cineasta marxista Jean-Marie Straub ou do brasileiro Glauber Rocha, por exemplo, da mesma forma, e o Faustão poderá sair de cena. A televisão produz o esquecimento, já o bom cinema - do ponto de vista da crítica marxista, desalienador - produz a reminiscência daquilo que não deve ser lembrado para continuação da dominação cíclica. 
Aproveitando o gancho de relembrar filmes, o cinema é um grande agente da indústria cultural. Originou-se no final do século XIX, já dentro de um capitalismo moderno, consequentemente, com a necessidade de atingir grandes públicos consumidores e se tornando um instrumento importante como fator de alienação - em especial, o produzido na grande indústria cultural, como Hollywood e Disney. As artes plásticas sofreram um processo de transformação nesse período, pois, antes, os artistas, ao concluírem as suas obras, desejavam que elas fossem vistas por uma ou poucas pessoas, porém, com o advento da fotografia, que atingia maior número de pessoas, devido à sua reprodução, os artistas necessitam alcançar maiores mercados, saindo da exclusiva relação com os mecenas. Entretanto, o cinema se diferencia das artes plásticas e da literatura, pois trata-se de uma criação coletiva para a sua produção, o que dá uma exigência de atingir grandes públicos, tornando-se cultura de massas.

O potencial de alienação e de atingir grandes públicos foi fator preponderante para regimes totalitários, com apelos nacionalistas, usarem o cinema para propagar ideais. A Alemanha nazista é um grande (senão, o maior) exemplo desse tipo de cenário. $\mathrm{O}$ uso controlado da cultura e da arte foi uma grande arma para a manipulação do povo alemão, não só o cinema, mas também livros, peças teatrais, programas de rádio, exposições em museus, galerias de artes etc., todos com a finalidade de tornar natural a violência cotidiana do regime, além de disseminar os valores e ideais a serem assimilados à sociedade. Durante o Terceiro Reich, os nazistas se empenharam profundamente naquilo que eles acreditavam ser uma "guerra cultural" (CARVALHO, 2020). Uma espécie de embate simbólico, no plano das letras e imagens; uma maneira de ganhar mentes e corações, já que são os meios por meio dos quais é dado um rosto ao país, seu povo e sua realidade, tornando assim a cultura como mais um recurso político.

$\mathrm{Na}$ atualidade, vemos que esse tipo de propaganda se transferiu para a internet de modo geral, seja em redes sociais, em plataformas de vídeos ou por qualquer busca dentro desse mundo virtual, onde não se pode ter controle das informações e sua veracidade. A tecnologia é a ideologia da contemporaneidade. $\mathrm{O}$ uso da tecnologia se tornou mais recorrente, como uma das consequências da pandemia do novo coronavírus. Durante esse período, tem havido inúmeras discussões em fóruns na internet e nas próprias redes sociais sobre questões antifascistas que se tornaram mais presentes, como, por exemplo, as decorrentes da onda de protestos antirracistas estadunidenses, iniciados pelo assassinato de George Floyd ${ }^{17}$, e de

17 George Floyd foi um afro-americano assassinado em Minneapolis, no dia 25 de maio de 2020, estrangulado por um policial branco que se ajoelhou em seu pescoço durante uma 
movimentos antidemocráticos presentes no Brasil, alguns apoiados pelo próprio Presidente da República.

Com isso surge, consequentemente, a questão: como ser contra o fascismo sem ser contra o capitalismo? Aqueles que lamentam a barbárie fascista, que tem sua base na própria barbárie capitalista, são como pessoas que desejam comer carne sem matar o boi. E também não se importam pela morte do animal se o açougueiro tiver lavado as mãos. O dramaturgo Bertolt Brecht diz, em seu texto O fascismo é a verdadeira face do capitalismo $(1935)^{18}$.

o fascismo é uma fase histórica do capitalismo; neste sentido, é algo novo e ao mesmo tempo antigo. Nos países fascistas, o capitalismo continua a existir, mas apenas na forma de fascismo; e $o$ fascismo apenas pode ser combatido como capitalismo, como a forma de capitalismo mais nua, sem vergonha, mais opressiva e mais traiçoeira.

Em um momento histórico atípico como o da pandemia atual, querendo ou não, para uma maior parte da população, tornaram-se visíveis as falhas do capitalismo, mesmo que muitos não o vejam como real âmago das opressões e da desigualdade, seja de classe, de raça ou de gênero.

De um lado, percebemos que os que lutam contra a ideologia vigente e todo o aparato desse sistema classicista ainda não são suficientes para a ruptura dessa ordem; de outro, observamos cada vez mais uma anestesia social, em que a grande massa segue mantida sob controle, mesmo vivenciando em suas vidas e tendo acesso todos os dias a informações sobre acontecimentos sociais, econômicos e políticos, cujo alcance nunca foi tão dinâmico, graças ao avanço tecnológico. Apesar da aparente insatisfação geral, a indignação e sensação de mudança se limita a isso, um acontecimento que te deixa com raiva ou triste e, logo após, um vídeo engraçado que te faz rir e esquecer o mundo real, como só mais uma informação que se viu rolando, incansavelmente, no feed de notícias nas redes sociais ou que se ouviu sem muita atenção na TV, fato que torna muito mais preocupante o nosso futuro como civilização.

A forma de dominação organizadamente articulada é tocada por todos os instrumentos rigorosamente afinados e regidos pelas mãos fantasmas do Capital, tornando-se uma sinfonia da destruição aos ouvidos dos lúcidos, mas soando como

abordagem por, supostamente, usar uma nota falsificada de vinte dólares em um supermercado. Floyd morreu asfixiado. Sua morte desencadeou uma onda de protestos antirracistas pelos EUA e outros países ao redor do mundo.

18 Texto de 1935, conforme tradução de Richard Winston para a revista Twice a Year. Textos escolhidos de Twice a Year, 1938-48. Syracuse University Press, 1964. Disponível em: https:// www.marxists.org/portugues/brecht/1935/mes/fascismo.htm. Acesso em: 03.08.2020. 
um belo canto da sereia para os leigos e para quem assiste de camarote a esse concerto. Tomemos um dos produtos da própria indústria cultural para expressar esse pensamento. No filme Matrix (1999), Morpheus diz para Neo: "Você precisa entender, a maioria dessas pessoas não está preparada para despertar. E muitas delas estão tão inertes, tão desesperadamente dependentes do sistema, que irão lutar para protegê-lo".

As subjetividades que no coletivo constituem o que denominamos de sociedade e dão significados ao mundo objetivo estão seguindo um caminho para ficarem padronizadas, como modelos uniformes em uma linha de produção. Imaginam que existe um livre arbítrio, já que se produz tanto e de tantas maneiras, mas não se percebem moldados pela sociedade em que vivem. Portanto, o que existe é a falsa sensação de liberdade, por apenas fazer escolhas entre A, B ou C e não reparar na possibilidade de questionar ou negar o sistema alfabético em si. Diz Marx, em seu discurso sobre o problema do livre-câmbio, em Miséria da Filosofia (1946, p. 194):

vocês, milhares de trabalhadores que sucumbem, não se desesperem. Vocês podem morrer tranquilos. Sua classe não desaparecerá. Será sempre suficientemente numerosa para que o capital possa dizimá-la, sem o temor de liquidá-la totalmente.

Aqui, neste comentário ácido, parece-nos que Marx está falando dos dias atuais. Pois, o descaso com as vidas perdidas de incontáveis trabalhadores (não devemos nos esquecer da subnotificação) por parte de governantes, locais e mundo afora, nos permite inferir que não fazem falta. São também incontáveis os homens-massa, como diria Sánchez Vázquez (1978), os que se vão, não chegam sequer a dificultar a reprodução do Capital.

A seguir, vamos nos voltar para a produção de músicos brasileiros e estrangeiros, buscando desvelar as estratégias que têm sido usadas na divulgação de trabalhos artísticos durante a pandemia. Mais especificamente, queremos compreender o uso que artistas têm feito do ferramental tecnológico disponível, no sentido de efetivar (ou não) a função da arte na vida das pessoas. Estamos supondo que a condição de isolamento físico, necessária ao controle do vírus da covid-19, ampliou o uso dessas tecnologias pela impossibilidade da realização presencial de shows, concertos etc. Pensamos, pois, que, neste momento histórico, configura-se uma "indústria do isolamento", como apontado no título deste texto. Entende-se essa "indústria" como uma adaptação da indústria cultural para a conjuntura que se pôs durante a pandemia, com o objetivo de continuar e até implementar o consumo de bens culturais como mercadorias; porém, agora mais que antes, de forma virtual ou até mesmo em situações restritas - como o reavivamento dos 
antigos drive-in, não apenas para o consumo do cinema, mas também eventos artísticos diversos, como shows, por exemplo. A nosso ver, é possível falar em "indústria do isolamento" com o apoio de Ludovico Silva (2017, p. 179, grifo do autor), quando elabora o seu conceito de "mais-valia ideológica". Vejamos.

\begin{abstract}
Pois se trata [a indústria cultural], em primeiro lugar, de uma indústria: indústria material, como qualquer outra indústria capitalista, com suas relações de produção e sua mais-valia material: um dos ramos da indústria do capitalismo contemporâneo. Mas, além disso, é cultural: se dedica à produção de todo tipo de valores e representações (“imagens") destinadas ao consumo massivo, ou seja: é uma indústria ideológica, produtora de ideologia no sentido estrito, destinada a formar ideologicamente as massas, a dotá-las de "imagens", valores, ídolos, fetiches, crenças, representações etc., que tendem a preservar o capitalismo.
\end{abstract}

E é [indústria] do isolamento, pois se trata de explorar (no sentido capitalista: econômica e ideologicamente), sem muitos escrúpulos, a condição de isolamento físico a que fomos constrangidos desde o agravamento do contágio (aqui em nosso país, a partir de meados de março de 2020) ${ }^{19}$.

A principal questão que gostaríamos de responder pode ser assim formulada: considerando a obra de arte como trabalho criativo humano que encerra a possibilidade de elevação das consciências; mas, por outro lado, a submissão dessa possibilidade, sob o capitalismo, à lógica da mercantilização; e, desse modo, entendendo que o consumo mais extenso e profundo é o da arte de massas; têm os artistas se valido desses instrumentos tecnológicos para promover a superação da alienação?

\title{
MÚSICA NA QUARENTENA: REFLEXÕES
}

Aqui, não é nosso objetivo apresentar um vasto levantamento estatístico acerca da produção artística online. Faremos, outrossim, algumas reflexões, a partir dessa produção, na tentativa de desvelar o papel do artista e da arte, sobretudo nesse momento que estamos vivenciando. Desde o início da pandemia, com a imposição de isolamento físico, adiamentos e cancelamentos de eventos, artistas reforçaram o uso de redes sociais e plataformas de compartilhamento de conteúdo. Nesse sentido, assistimos algumas lives e também outras formas de produção, como postagens e videoclipes, de artistas brasileiros e estrangeiros, de diferentes gêneros e estilos musicais, que aconteceram no período de 21 de abril a 08 de agosto de

19 Não ignoramos que, para a vasta maioria da população, esse isolamento não pode se realizar. Entretanto, no que toca às apresentações musicais ao vivo, as restrições estão mantidas, até o momento. 
2020. Aqui, apresentaremos as que consideramos as mais representativas para as questões que nos movem neste texto.

Considerando as diferenças entre esses formatos de publicação ou divulgação dos trabalhos artísticos, o foco da análise precisou se voltar também para diferentes elementos no trato do material coletado. Assim, nas lives, quisemos desvelar e compreender o conteúdo das mensagens transmitidas pelos artistas ao seu público: trataram de questões ligadas à pandemia? Em caso afirmativo, quais questões foram colocadas? Da mesma forma, nas postagens do campo erudito. Nesse sentido, nas lives e postagens do campo erudito foram analisados não os enunciados musicais, mas os enunciados verbais. Já nos videoclipes, voltamo-nos para as letras das músicas, uma vez que não há, nesse veículo, o contato simultâneo com o público; e, por outro lado, trata-se de músicas compostas justamente nesse período de pandemia e que abordam esse tema. Vejamos.

De acordo com Souza Júnior et al. (2020), Saiba (2020) e Lives (2020), a cantora, compositora e instrumentista brasileira Marília Mendonça aparece em primeiro lugar entre as lives da plataforma YouTube, com maior número de espectadores simultâneos em todo o mundo, no ano de 2020, até o dia 08 de agosto. Foram 3,3 milhões de espectadores. Esse número, porém, não chega a ser tão espantoso, uma vez que o sertanejo é o estilo musical mais apreciado em nosso país (ECAD, 2020). A live à qual nos referimos foi a do dia 08 de maio, intitulada "Live Marília Mendonça - \#LiveLocalMariliaMendonca" ${ }^{20}$, fez parte da campanha "Fique Em Casa e Cante \#Comigo" e teve 3h30 de duração. Vejamos no quadro abaixo o conteúdo das falas da artista, na interação possível com o seu público presente-distante.

20 MENDONÇA, Marília. Live Marília Mendonça. 2020. (3h29m49s). Disponível em: https://www.youtube.com/watch?v=s-aScZtOfbM. Acesso em: 14.06.2020. 
Quadro 1. Lives do Campo Popular: Marília Mendonça

\begin{tabular}{|c|c|c|}
\hline Mensagem & Contexto & Momentos \\
\hline $\begin{array}{l}\text { Indica e instiga para que } \\
\text { o público doe para o } \\
\text { programa de impacto } \\
\text { social Mesa Brasil por meio } \\
\text { do } Q R \text { Code disponível na } \\
\text { live. }\end{array}$ & $\begin{array}{l}\text { Nos intervalos das músicas, a artista convida } \\
\text { os espectadores a colaborarem e comenta ações } \\
\text { do Mesa Brasil e outros programas de impacto } \\
\text { social. Nos momentos finais da live, em 139:39, } \\
\text { traz a informação de quantidades de alimentos } \\
\text { arrecadados durante a apresentação; }\end{array}$ & $\begin{array}{c}36: 57 \\
70: 00 \\
87: 50 \\
124: 37 \\
139: 39 \\
160: 30\end{array}$ \\
\hline $\begin{array}{l}\text { Comenta sobre programas } \\
\text { de apoio ao pequeno } \\
\text { empreendedor e pequeno } \\
\text { negócio, programa Cuide } \\
\text { do Pequeno Negócio da } \\
\text { empresa Stone, anunciada } \\
\text { como parceira da live. }\end{array}$ & $\begin{array}{l}\text { Surge como gancho após os comentários sobre a } \\
\text { importância e demais informações referente às } \\
\text { doações. Além de se tratar de uma plataforma } \\
\text { de apoio e incentivo ao consumo do comércio } \\
\text { local, a artista incentiva o uso de redes sociais } \\
\text { para aumentar a visibilidade desses pequenos } \\
\text { empreendimentos locais. }\end{array}$ & $\begin{array}{l}36: 00 \\
107: 28 \\
117: 14 \\
187: 50\end{array}$ \\
\hline $\begin{array}{l}\text { Apontamento de ações de } \\
\text { impacto social de grandes } \\
\text { empresas e também das } \\
\text { "parceiras" da live. }\end{array}$ & $\begin{array}{l}\text { Essas empresas surgem destacadas como } \\
\text { associadas a ações de impacto social, tanto } \\
\text { envolvidas com as doações e o programa de } \\
\text { apoio ao pequeno empreendedor (Stone) quanto } \\
\text { envolvidas com ações não relacionadas à live } \\
\text { (Havaianas). }\end{array}$ & $\begin{array}{l}36: 00 \\
36: 57 \\
117: 14 \\
124: 37 \\
166: 21\end{array}$ \\
\hline
\end{tabular}

Fonte: Os autores, 2020.

Durante a live, a artista recebeu uma mensagem do então ministro da saúde Henrique Mandetta, "Marília Mendonça, nosso cumprimento, que você faça uma boa live e que as pessoas curtam em casa, e que a gente não aglomere". Respondendo a esse comentário, a artista comenta, uma única vez durante a live, sobre a importância de os espectadores seguirem as recomendações do Ministério da Saúde. As empresas patrocinadoras da live, que aparecem como parceiros, são extensamente citadas e apontadas como promotoras das ações de impactos sociais.

No dia 21 de abril aconteceu a live "Sandy e Junior | LIVE"21, com a participação dos artistas Sandy, Júnior e Lucas Lima. A transmissão ao vivo, na plataforma YouTube, foi excluída; assim, para a nossa tomada de dados, foi utilizada a cópia da live, disponível no mesmo site. Também fez parte da campanha "Fique Em Casa e Cante \#Comigo". Na maior parte dos intervalos, os artistas leram os comentários dos espectadores e comentaram a quantidade de alimentos arrecadados. Vejamos no quadro abaixo.

21 SANDY \& Junior. Sandy e Junior | LIVE. 2020. (2h40m26s). Disponível em: https:// www.youtube.com/watch?v=8fTOh_sM36I. Acesso em: 26.06.2020. 
Quadro 2. Lives do Campo Popular: Sandy, Júnior e Lucas Lima

\begin{tabular}{|c|c|c|}
\hline Mensagem & Contexto & Momentos \\
\hline $\begin{array}{l}\text { Reforço da ideia de que o } \\
\text { objetivo da live é arrecadar } \\
\text { doações para pessoas em } \\
\text { situação de vulnerabilidade. } \\
\text { Instigaram os espectadores a } \\
\text { doar por meio do QR Code da } \\
\text { empresa PicPay, responsável } \\
\text { por receber o dinheiro das } \\
\text { doações. }\end{array}$ & $\begin{array}{l}\text { Majoritariamente, em todos os intervalos } \\
\text { entre músicas, os artistas comentaram ou } \\
\text { receberam mensagens da empresa parceira } \\
\text { da live, Casas Bahia, sobre a quantidade } \\
\text { de alimentos arrecadados e instigaram os } \\
\text { espectadores a atingirem determinadas metas } \\
\text { de doações. }\end{array}$ & $\begin{array}{c}2: 02 \\
16: 48 \\
23: 00 \\
26: 00 \\
37: 20 \\
53: 20 \\
85: 40 \\
106: 00 \\
113: 40\end{array}$ \\
\hline $\begin{array}{l}\text { Recomendações para os } \\
\text { espectadores quanto ao uso de } \\
\text { máscara e isolamento social. } \\
\text { Os riscos de exposição e a } \\
\text { importância do trabalho dos } \\
\text { profissionais de saúde. }\end{array}$ & $\begin{array}{l}\text { Em alguns intervalos, os artistas comentaram } \\
\text { sobre experiências próprias ou de pessoas } \\
\text { próximas quanto ao isolamento. Essas } \\
\text { experiências envolvem a necessidade do uso } \\
\text { de máscara, ajuda às pessoas do grupo de } \\
\text { risco quanto a necessidade de sair de casa } \\
\text { e também a importância do trabalho dos } \\
\text { profissionais de saúde. }\end{array}$ & $\begin{array}{c}53: 50 \\
109: 40 \\
155: 14\end{array}$ \\
\hline
\end{tabular}

Fonte: Os autores, 2020.

Apesar de ter características comuns a várias outras lives que ocorreram no contexto de isolamento físico, como a presença de empresas patrocinadoras promovendo ações de doação ou responsáveis pelo destino das doações arrecadadas, a live "Sandy \& Junior" tocou diretamente em questões da realidade de pessoas que vivem com maiores riscos de contágio. Por outro lado, assim como nas outras lives que assistimos, as questões de ordem política, como a responsabilidade dos nossos governantes ante a situação trágica que vivenciamos em momento algum foram abordadas.

Assim também ocorreu com as postagens e lives do gênero erudito às quais $\operatorname{assistimos}^{22}$. Em geral, os artistas apenas se referiram aos cuidados que se deve

22 RENEÉ FLEMING AND EVGENY KISSIN - AVE MARIA. 2020. (5m43s). Disponível em: https://www.youtube.com/watch?v=MoFQ92rZT3o. Acesso em: 02.06.2020.

MARIAM BATSASHVILI - Concert from home / \#Stayhome and Enjoymusic \#Withme. 2020. (31m22s). Disponível em: https:/www.youtube.com/watch?v=f7oUdzGy89I. Acesso em: 03.06.2020.

MARIAM BATSASHVILI - Concert from home 2 / \#Stayhome and Enjoymusic \#Withme. 2020. (19m48s). Disponível em: https://www.youtube.com/watch?v=YHUnqTJu5Bg. Acesso em: 03.06.2020. 
ter consigo mesmo e com os outros e às possibilidades oferecidas pelas tecnologias de poder levar música para as pessoas, neste momento de isolamento físico. Outras vezes, apontam os cuidados que foram tomados para a realização da live ou da postagem (distanciamento, uso de máscaras, higienização do ambiente e dos instrumentos musicais etc.). Não chega a surpreender que a comunicação verbal seja reduzida, no âmbito desse gênero musical, porque o modo de interação artista-público em concertos e recitais é, na maioria dos casos, mediado "apenas" pela música. Por outro lado, vivemos uma situação extrema que mereceria um envolvimento e posicionamento mais radical dos artistas. Da mesma forma que nas produções do campo popular, há solicitação de doações, mas, no caso do material ao qual tivemos acesso, foram doações para outros artistas. Observemos o quadro abaixo.

Quadro 3. Postagens e Live do campo erudito

\begin{tabular}{|c|l|}
\hline $\begin{array}{c}\text { Postagens } \\
\text { e live }\end{array}$ & \multicolumn{1}{c|}{ Mensagens } \\
\hline $\begin{array}{c}\text { Fleming e } \\
\text { Kissing }\end{array}$ & $\begin{array}{l}\text { Durante o primeiro minuto, os artistas relembram os “tempos difíceis" que } \\
\text { vivenciamos e as obrigações de cuidarmos de nós mesmos e dos que amamos. } \\
\text { Ressaltam as possibilidades tecnológicas de superar o isolamento físico com } \\
\text { postagens como a que farão e dedicam a obra executada (Ave Maria - R. Schubert) } \\
\text { aos trabalhadores da saúde. Na descrição do vídeo, há indicação de endereços } \\
\text { eletrônicos para doação a outros artistas. }\end{array}$ \\
\hline Batsashvili & $\begin{array}{l}\text { Da mesma forma, os primeiros minutos das postagens são dedicados a situar o } \\
\text { momento em que vivemos. A artista expressa seu desejo de que os espectadores } \\
\text { estejam bem e saudáveis, aponta o quão pouco usual, para ela, é essa forma de } \\
\text { interação virtual com o público, mas destaca a possibilidade de mais pessoas } \\
\text { terem acesso a esse tipo de concerto. Afirma, ainda, que sua intenção é levar um } \\
\text { pouco de alegria e esperança para as pessoas que a ouvirão. }\end{array}$ \\
\hline $\begin{array}{c}\text { Live } \\
\text { OSESP (08 } \\
\text { de agosto } \\
\text { de 2020) }\end{array}$ & $\begin{array}{l}\text { As cenas iniciais mostram os preparativos do palco para os ensaios - estantes } \\
\text { e cadeiras colocadas a maior distância e separadas por placas de acrílico, } \\
\text { higienização do local, cuidados de higiene pessoal. Alguns artistas dão seu } \\
\text { depoimento sobre a emoção de voltar à Sala. Aos 18’37”, o diretor artístico da } \\
\text { OSESP, Arthur Nestrovski, dá as boas-vindas aos ouvintes e anuncia o modo de } \\
\text { funcionamento da orquestra, durante a pandemia e o repertório do concerto. Aos } \\
\text { 24', começa o concerto. }\end{array}$ \\
\hline
\end{tabular}

Fonte: Os autores, 2020.

MARIAM BATSASHVILI - Concert from home 3 / \#Stayhome and Enjoymusic \#Withme. 2020. (18m02s). Disponível em: https://www.youtube.com/watch?v=MoFQ92rZT3o. Acesso em: 03.06.2020.

\#AOVIVO Osesp, sob regência de Emmanuele Baldini, toca Beethoven. 2020. (1h07m40s). Disponível em: https://www.youtube.com/watch?v=3Ai8tYHdDdU. Acesso em: 11.08.2020. 
Como se vê, as menções à pandemia e à covid-19 são, digamos, bastante discretas, considerando a gravidade da situação; por outro lado, não há referência a patrocinadores, parcerias e produtos, como no caso das lives do campo popular. Perguntamo-nos, entretanto: trata-se de uma tentativa de não ofuscar as obras musicais dos grandes mestres com questões alheias a elas? Haveria aqui um indício de entendimento de que a Arte (assim, com "A" maiúsculo) está acima da vida humana?

Vejamos agora algumas produções musicais de outro estilo, dentro do campo popular, conhecido como cultura hip hop. O sentido é ampliar o espectro de análise e desvelar possíveis contradições entre os conteúdos da cultura de massa consumidos no Brasil. Trouxemos, então, produções musicais ${ }^{23}$ que tratam diretamente de questões do momento de crise atual.

Quadro 4. Produções Musicais da cultura hip hop

\begin{tabular}{|l|l|l|}
\hline \multicolumn{1}{|c|}{ Estilo } & $\begin{array}{c}\text { Data de lançamento/ } \\
\text { número de } \\
\text { visualizações }\end{array}$ & \multicolumn{1}{c|}{ Sobre o que trata a letra da música } \\
\hline $\begin{array}{l}\text { Mc Robs - Vidas } \\
\text { negras importam/ } \\
\text { Funk consciente }\end{array}$ & $\begin{array}{l}\text { 13 de junho de 2020/ } \\
\text { oficial) }\end{array}$ & $\begin{array}{l}\text { O cantor relata a violência policial sofrida } \\
\text { especificamente pelos negros. Cita a pandemia } \\
\text { e a dificuldade das comunidades e periferias de } \\
\text { enfrentar o vírus. Também é mencionado o caso } \\
\text { da morte de George Floyd, que desencadeou } \\
\text { os protestos recentes antirracismo. Trazendo a } \\
\text { contradição e pedindo mudanças da realidade } \\
\text { vivida. }\end{array}$ \\
\hline $\begin{array}{l}\text { Daniel Ordem } \\
\text { Própria - } \\
\text { Apocalipse } \\
\text { poético/ }\end{array}$ & $\begin{array}{l}\text { 21 de abril de 2020/ } \\
\text { Rap }\end{array}$ & $\begin{array}{l}\text { O cantor cita a luta indígena por suas terras } \\
\text { contra grandes fazendeiros/latifundiários. } \\
\text { Trata diretamente da pandemia atual, com } \\
\text { fortes críticas ao posicionamento do governo, } \\
\text { aos que batem panelas como protesto, às lives } \\
\text { pretensiosas cheias de propagandas e à angústia } \\
\text { humana vivida nesse momento. }\end{array}$ \\
\hline
\end{tabular}

23 Mc Robs. Vidas negras importam. Disponível em: https://www.youtube.com/ watch? $\mathrm{v}=$ iw6RLrHOlXE. Acesso em: 28.01.2021.

Daniel Ordem Própria. Apocalipse poético. Disponível em: https://www.youtube.com/ watch? $\mathrm{v}=\mathrm{hmbMDDwtbL}$. Acesso em: 28.01.2021.

Rincon Sapiência. Quarentena (Verso livre). Disponível em: https://www.youtube.com/ watch?v=k_gsUc7LD10. Acesso em: 28.01.2021. 


\begin{tabular}{|l|l|l|}
\hline $\begin{array}{l}\text { Rincon Sapiência } \\
\text { - Quarentena } \\
\text { (Verso livre)/ }\end{array}$ & $\begin{array}{l}8 \text { de maio de 2020/ } \\
245.471 \text { (videoclipe } \\
\text { oficial) }\end{array}$ & $\begin{array}{l}\text { O cantor fala da impossibilidade de exibição do } \\
\text { consumo, como carros e roupas caras, já que se } \\
\text { recomenda ficar em casa. Cita a impossibilidade } \\
\text { da televisão produzir conteúdo, optando pela } \\
\text { repetição de programas e jogos de futebol. } \\
\text { Alega que "votaram errado na urna", criticando } \\
\text { a posição do governo atual, além de ressaltar as } \\
\text { dúvidas que surgem sobre a vida pós-pandemia. }\end{array}$ \\
\hline
\end{tabular}

Fonte: Os autores, 2020.

As músicas do quadro acima ${ }^{24}$, apesar de fazerem parte de estilos considerados como cultura de massas (funk e hip hop/rap), foram, em comparação com as lives que apresentamos anteriormente, muito menos acessadas. Como já vimos, a cantora Marília Mendonça conseguiu alcançar 3,3 milhões de visualizações simultâneas, enquanto o videoclipe mais visto do quadro por nós elaborado, de Rincon Sapiência, teve cerca de 245,4 mil visitantes (considerando que essa contagem é cumulativa quando se trata de um conteúdo postado no YouTube permanentemente, diferente dos conteúdos ao vivo, que muitas vezes saem do ar logo após o término do evento).

Poderíamos ainda citar outras produções musicais da cultura hip hop que foram identificadas durante nossa busca: Traidor, de Eduardo Taddeo (ex-Facção Central); Quarentena, de MV Bill; Pela paz e pra guerra, de Daniel Ordem Própria e MV Bill; e O pobre tem seu lugar, de Theus Costa e Mc Robs.

Pararemos por aqui com a exposição desse material empírico. Acreditamos que, mesmo sendo limitado, serviu para dar ao leitor um panorama representativo das produções musicais que vêm sendo feitas por artistas de diferentes gêneros e estilos durante a pandemia que vivenciamos desde 2020. Pensemos, agora, sobre essas produções à luz do referencial teórico que assumimos.

Na maioria das vezes, o objetivo explicitado pelos próprios artistas foi o de entreter as pessoas que estão em isolamento. Isso poderia ser entendido como um ponto positivo; por outro lado, aponta para uma perspectiva da arte como entretenimento, com função de fazer as pessoas se "desligarem" dos problemas, como algo que opõe: trabalho/desprazer/razão versus entretenimento/prazer/emoção. Como afirma Frederico (2013), essa arte também é importante e tem um lugar na vida humana, mas é forçoso reconhecer que não promovem conscientização. Manter o

$24 \quad$ Seria interessante e pertinente fazer uma análise estética aprofundada dessas letras, mas fugiria aos limites deste trabalho. Fica, portanto, para uma próxima oportunidade. 
sustento dos artistas e obter doações para pessoas em situação de vulnerabilidade também são outros pontos que poderíamos considerar positivos. Entretanto, da perspectiva materialista histórica e dialética, que fundamenta nossas reflexões, é preciso desvelar os múltiplos determinantes de tais ações - sem desmerecer seu valor premente para aqueles que delas vieram a se beneficiar.

Em alguns casos, sobretudo quando se enfatizou repetidas vezes o apoio dos patrocinadores, essas ações denotam o processo de mercantilização que sofre a arte e, também, o artista na sociedade capitalista (SÁNCHEZ VÁZQUEZ, 1978, ADORNO; HORKHEIMER, 1985, SILVA, 2013). Embora se possa pensar que alguma necessidade humana estivesse sendo satisfeita, nesse caso, o processo assumiu uma feição ainda mais estranhada: ao mesmo tempo em que é mercadoria, a arte ajuda a vender (convencer?) - estamos nos referindo ao papel dos artistas na promoção da imagem de seus patrocinadores como benfeitores, filantropos etc. Não deixa de se configurar como ocultamento das relações sociais engendradas pelo sistema capitalista - a exploração dos trabalhadores por aqueles que detém os meios de produção.

Ludovico Silva, ao postular a ideia de "mais-valia ideológica", como a expropriação da consciência dos indivíduos, da sua "força de trabalho intelectual" (SILVA, 2013, p. 188, grifos do autor), afirma ainda que alguns artistas são, eles mesmos, "os maiores produtores de mais-valia ideológica para o sistema" (SILVA, 2013, p. 191, grifos do autor). São, ao mesmo tempo, explorados e exploradores a serviço do sistema; arte e artista tornam-se, assim, os melhores ideólogos do capital. Por isso, o filósofo venezuelano parte do termo "indústria cultural", de Adorno e Horkheimer, e o expande, afirmando tratar-se de "indústria ideológica".

Voltemos ao material empírico. Como vimos, a questão da pandemia e tudo o que a cerca não foi tocada em profundidade - exceção feita às produções da cultura hip hop e do funk. Quando apareceu, o enfoque foi a questão da sobrevivência: na live de Sandy \& Júnior, referiram-se aos profissionais de saúde, à necessidade de cuidados e às "obrigações" daqueles que podem ficar em isolamento, foram feitos agradecimentos aos que estão trabalhando etc.; na live de Marília Mendonça, referiu-se às pessoas que precisam continuar trabalhando e à necessidade de contribuir com os pequenos negócios locais; nas postagens dos artistas do campo erudito, da mesma forma, recomendou-se cuidado pessoal e com aqueles que nos cercam. Essas questões são importantes, mas tocam apenas a superfície do problema que vivenciamos, além de se correr o risco de naturalizá-lo. Ademais, promovem uma total desresponsabilização dos governantes frente às dificuldades pelas quais passa a maioria esmagadora da população. Não apontando para a 
função dos governantes ante a pandemia e dando destaque à atuação das empresas na solução dos problemas sociais, são reforçadas, subliminarmente, concepções muito caras à ideologia neoliberal que tem orientado a nossa política econômica ${ }^{25}$. Além disso, ao tirar a responsabilidade dos governantes, passa-se a responsabilizar o indivíduo - são as pessoas, individualmente, que têm que tomar os cuidados, manter o comércio ativo etc.

Embora reconheçamos que as pessoas estão precisando de alento, essas ações podem reforçar um certo conformismo diante da situação - uma perspectiva de que é só ter calma e esperar porque "vai passar" etc. Não estamos postulando a máxima "quanto pior, melhor", isso seria tripudiar sobre as angústias e os sofrimentos daqueles que não estão podendo satisfazer suas mínimas necessidades de sobrevivência. Mas não vimos reveladas, no material empírico, as possibilidades da arte como instrumento de superação da alienação - exceção feita à produção da cultura hip hop, sobre a qual já falaremos. Na maior parte das lives e postagens, a atuação dos artistas não chega a promover a elevação das consciências, no sentido de uma compreensão superior da vida; não promove, tampouco, a ação de transformação da realidade. Sendo assim, não há, na maioria dos casos, um uso contraditório dos instrumentos tecnológicos da indústria cultural a favor da ampliação das consciências, como era a nossa preocupação inicial.

Como dissemos, a exceção fica por conta das produções da cultura hip hop (nas letras dos rap e do funk, como se pode conferir no quadro 4), que tratam diretamente dos problemas enfrentados, sobretudo nesse momento, pelas populações periféricas. De fato, as manifestações culturais do hip hop têm, desde o início, esse caráter especificamente conscientizador. O quanto se alcança, efetivamente, em termos de conscientização nas comunidades de onde os artistas são oriundos, é assunto para um outro estudo.

É importante ressaltar que estamos cientes de que a situação apontada em nossas análises não é inédita ou conjuntural. Arte e artista, na sociedade capitalista, só a duríssimas penas conseguem se desvencilhar da lógica mercantilizante. Neste momento, porém, de agudização das contradições, a produção artística aqui apresentada - mais uma vez, com exceção dos rap e do funk - revela uma face ainda mais obscura do drama humano sob esse modo de organização da vida. Sobretudo em algumas das lives, a tragédia do drama humano parece servir de motivo para o "espetáculo". Não estamos tomando esse termo em sua acepção

\footnotetext{
25 Não estamos afirmando que os artistas tenham (ou não) consciência disso. Esse não é o aspecto em análise. Entretanto, lembramo-nos de que, sob a égide do capital, nenhum trabalhador é verdadeiramente livre.
} 
corriqueira, mas assumindo, com o pensador francês Guy Debord, a ideia da sociedade capitalista como sociedade do espetáculo. No livro que leva esse título, afirma em sua tese 1: "toda a vida das sociedades nas quais reinam as condições modernas de produção se anuncia como uma imensa acumulação de espetáculos" (DEBORD, 2003, p. 13).

Essa frase, em termos de forma e de conteúdo, muito se assemelha à primeira que lemos no volume I d'O Capital: "a riqueza das sociedades onde reina o modo de produção capitalista aparece como uma 'enorme coleção de mercadorias" (MARX, 2013, p. 113). Pensamos que essa semelhança não é casual. Mercadoria e espetáculo, nesses dois autores, compartilham, no mínimo, um elemento que gostaríamos de destacar: seu caráter fetichizador; ambos encobrem suas reais e mais profundas determinações e mostram apenas a face aparente, em geral, mais amena (notem-se os verbos: anunciar e aparecer, nas formulações de Debord e Marx, respectivamente). E o fetichismo é, pois, o fundamento material da alienação.

Então, por que dissemos que, em algumas lives, a tragédia do drama humano, talvez agora mais do que antes, parece servir de motivo ao espetáculo? Em primeiro lugar, por se configurarem como a mercantilização da própria tragédia - o que se viu, em alguns casos, foi venda, com fim de obter lucro (ainda que, no momento, esses lucros possam não ser financeiros). Em segundo, por se fundar na ideia de entretenimento, de fazer as pessoas espairecerem, se esquecerem das dificuldades, o que, ao fim e ao cabo, nos distancia de todos os que não estão em condições de usufruir do entretenimento (os que não têm casa, os que não têm televisão, celular, internet, os que não têm o que comer, os que não têm como lavar as mãos, os que estão trabalhando, os que estão nos hospitais, nos cemitérios). Isso nos entorpece o espírito e nos desconecta de nossa condição humana. Tudo diverge da função da arte e do artista na vida das pessoas, conforme os autores que trouxemos ao debate (VIGOTSKI, 1998; SÁNCHEZ VÁZQUEZ, 1978).

Diz Debord: "o espetáculo é a conservação da inconsciência na modificação prática das condições de existência" (DEBORD, 2003, p. 23); "representa concretamente uma fabricação de alienação" (DEBORD, 2003, p. 26). O oposto do que deve ser a arte - esquecer os problemas não move as pessoas à ação transformadora da realidade.

\section{CONSIDERAÇÕES FINAIS}

Como palavras finais, vamos retomar rapidamente o percurso que traçamos neste texto. Para responder à nossa questão sobre o uso dos aparatos da indústria 
cultural na superação da alienação, sobretudo, durante a pandemia da covid-19, assumimos como fundamento teórico o materialismo histórico e dialético nas formulações de Vigotski (1998) - sua concepção de arte e papel da arte na vida humana - e de Sánchez Vázquez (1978) - sobre as determinações da arte no capitalismo. Buscamos também a contribuição de Adorno e Horkheimer (1985), para a explicitar o conceito de indústria cultural, e de Ludovico Silva (2017), que postula a ideia de mais-valia ideológica como a energia intelectual sequestrada do trabalhador em seus momentos de não-trabalho.

A resposta que alcançamos, neste estudo, não pretende ser definitiva, mas, sem dúvida, expressa algo sobre a sociedade em que vivemos. Não conseguimos vislumbrar, na maioria do material analisado, aquela força transformadora, aquele potencial catártico, antialienação ao qual se refere Vigotski (1998). O artista submetido à lógica da mercantilização, coisificado, não pode oferecer ao público uma criação que seja, efetivamente, expressão de sua humanidade, de suas forças essenciais; tampouco pode atuar de maneira revolucionária. Ao contrário, acreditamos que suas ações apenas podem gerar conformismo e acomodação, submissão e passividade - alienação. Quem perde e quem ganha com isso? Indiscutivelmente, ganha a ideologia dominante. Perde a arte e perdem todos os homens. As exceções, porém, denotam as possibilidades da arte e do artista na elevação das consciências, mesmo sob a égide do capital. A tarefa, entretanto, é complexa. Não nos iludamos! "Para arrancar os homens coisificados, alienados, da arte de massas - que consomem diariamente - e fazê-los gozar uma autêntica arte, deve-se primeiro arrancá-los de sua coisificação ou alienação" (SÁNCHEZ VÁZQUEZ, 1978, p. 299, grifos do autor).

Finalizamos com a emblemática frase de Lênin, "sem teoria revolucionária, não há movimento revolucionário" (LÊNIN, 2010, p. 81). O autor expressa aqui a importância da produção teórica, tão necessária quanto a prática, nas lutas econômicas e políticas pela transformação social. Isso não exclui a arte, muito pelo contrário.

\section{REFERÊNCIAS}

ADORNO, Theodor W.; HORKHEIMER, Max. Dialética do Esclarecimento. Rio de Janeiro: Jorge Zahar Editor, 1985.

BOTELHO, Maurílio Lima. Epidemia econômica: Covid-19 e a crise capitalista. Blog da Boitempo, 2 Abr, 2020. Disponível: https://blogdaboitempo.com. 
br/2020/04/02/epidemia-economica-covid-19-e-a-crise-capitalista/?shared=ema il\&msg=fail. Acesso em: 16.06.2020.

BOTELHO, Maurílio Lima.Um mundo afogado em capital: a queda global da taxa de juros e a nova rodada da crise estrutural do capitalismo. Blog da Boitempo, 29 Nov, 2019. Disponível em: https://blogdaboitempo.com.br/2019/11/29/ummundo-afogado-em-capital-a-queda-global-da-taxa-de-juros-e-a-nova-rodadada-crise-estrutural-do-capitalismo/. Acesso em: 16.06.2020.

BLEGER, José. Prólogo. In: POLITZER, Georges. Critica de los fundamentos de la psicología y el psicoanalisis. Davalos/Hernández: Libreros Editores, 1964. CARVALHO, Bruno L. P. O controle da cultura e da arte na Alemanha nazista(Artigo). In: Café História - história feita com cliques. Disponível em: https://www.cafehistoria.com.br/o-controle-da-cultura-e-da-arte-na-alemanhanazista/. Acesso em: 08.08.2020

DEBORD, Guy. A sociedade do espetáculo. eBooksBrasil, 2003. Disponível em: https://www.marxists.org/portugues/debord/1967/11/sociedade.pdf. Acesso em 27/09/2020.

ECAD comprova: sertanejo é o ritmo mais ouvido no Brasil. Ecad. 2018. Disponível em: https://www3.ecad.org.br/em-pauta/Paginas/ecad-comprovasertanejo-e-o-ritmo-mais-ouvido-no-brasil.aspx. Acesso em: 10.06.2020.

FREDERICO, Celso. A arte no mundo dos homens: o itinerário de Lukács. São Paulo: Expressão Popular, 2013.

FROMM, Erich. A arte de amar. 2a ed. São Paulo: Martins Fontes, 2015.

GOUVÊA, Marina Machado. A culpa da crise não é do vírus. In: MOREIRA, Elaine et al. (org.). Em tempos de pandemia: propostas para a defesa da vida e de direitos sociais. Rio de Janeiro: UFRJ. Centro de Filosofia e Ciências Humanas. Escola de Serviço Social, 2020. p. 19-28. Versão online disponível em: http:// www.cress-es.org.br/wp-content/uploads/2020/05/1_5028797681548394620. pdf\#pandemia.indd\%3A.22648\%3A229. Acesso em: 16.06.2020.

LÊNIN, Vladimir I. Que fazer? Problemas candntes do nosso movimento. São Paulo: Expressão Popular, 2010.

LIVES sertanejas dominam ranking mundial de audiência. Estadão, São Paulo, 20 de maio de 2020. Seção Cultura. Disponível em: https://cultura.estadao.com. br/blogs/divirta-se/lives-sertanejas-dominam-ranking-mundial-de-audiencia/. Acesso em: 10.06.2020. 
MATRIX. Direção: Lana Wachowski e Lilly Wachowski. Produção: Village Roadshow Pictures e Silver Pictures. Estados Unidos: Warner Bros, 1999. 1 DVD MARX, Karl. O Capital: crítica da economia política - livro I. São Paulo: Boitempo, 2013.

MARX, Karl. Manuscritos econômico-filosóficos. São Paulo: Boitempo, 2010.

MARX, Karl. Miséria da filosofia: resposta à Filosofia da Miséria do Sr. Proudhon. São Paulo: Flama, 1946.

MARX, Karl. A ideologia alemã. São Paulo: Boitempo, 2007.

ORTEGA Y GASSET, José. Rebelião das massas. eBook Brasil, 2005. Disponível em: http://www.leb.esalq.usp.br/leb/aulas/lce1302/ortega.pdf. Acesso em: 15.02.2021.

POLITZER, Georges. Crítica dos fundamentos da psicologia: a psicologia e a psicanálise. Piracicaba: Editora da UNIMEP, 1998.

RODRIGUES, Lucas de O. Sociedade de massa. Brasil Escola. Disponível em: https://brasilescola.uol.com.br/sociologia/sociedade-massa.htm. Acesso em: 21.05.2020.

SAIBA quem são os artistas sertanejos que dominam a lista das 10 lives musicais mais vistas do mundo. Movimento Country, 2020. Disponível em: https://www. movimentocountry.com/10-lives-mais-vistas. Acesso em: 10.06.2020.

SÁNCHEZ VÁZQUEZ, Adolfo. Convite à estética. Rio de Janeiro: Civilização Brasileira, 1999.

SÁNCHEZ VÁZQUEZ, Adolfo. As ideias estéticas de Marx. $2^{\text {a }}$ ed. Rio de Janeiro: Paz e Terra, 1978.

SILVA, Ludovico. A mais-valia ideológica. Florianópolis: Insular, 2017.

SOUSA JÚNIOR, J. H. de et al. "\# FIQUEEMCASA E CANTE COMIGO”: ESTRATÉGIA DE ENTRETENIMENTO MUSICAL DURANTE A PANDEMIA DE COVID-19 NO BRASIL. Boletim de Conjuntura (BOCA), v. 2, n. 4, p. 72-85, 2020.

TEOREMA. Direção: Pier P. Pasolini. Itália, 1968. 1 DVD

VIGOTSKI, Lev S. Psicologia da arte. São Paulo: Martins Fontes, 1998. 